\title{
Registered nurses' experiences and the challenges they face in relation to peripheral venous cannulation
}

\section{Ellen Gjerde}

Anestesisykepleier

International SOS (Medsite) AS

\section{Anne Moen}

\section{Professor}

Avdeling for sykepleievitenskap, Institutt for helse og samfunn, Universitetet i Oslo

\section{Silje Havrevold Henni}

Postdoktor

Avdeling for sykepleievitenskap, Institutt for helse og samfunn, Universitetet i Oslo

Peripheral venous cannulation

\section{Summary}


Background: The insertion of a peripheral venous catheter (PVC) is the most routinely performed invasive procedure carried out by registered nurses (RNs) in hospitals. Eighty per cent of all patients in hospital need a PVC. Nevertheless, RNs do not succeed in performing the procedure in one of three cases, particularly when the patient has difficult venous access. As a result, the patient is exposed to complications such as painful needlesticks, haematoma, arterial and nerve injuries in addition to a delay in medical treatment. RNs' knowledge of the PVC procedure has not been adequately investigated.

Objective: To describe registered nurses'(RNs) experiences when inserting PVCs and the challenges they face. This study will help improve RNs' skills, improve patient safety and their experience of the PVC procedure.

Method: We used a qualitative, descriptive design. We conducted two semistructured focus group interviews with altogether nine RNs to hear about their experiences and ascertain what challenges PVC insertion presented. The interviews were analysed by means of thematic analysis.

Results: All the RNs in the study were familiar with the PVC procedure and estimated that they inserted needles two or three times a week. Their experiences and the challenges they faced were particularly related to the patient's veins, their own skills and working conditions. All the informants provided examples of the challenges, such as non-visible or non-palpable veins and time conflicts. Time conflicts arose when the RNs had many work tasks to carry out at the same time in different places, and it was difficult to prioritise. RNs with less than five years' work experience, and those who lacked a sufficient volume of training describe greater challenges when inserting a PVC than experienced RNs.

Conclusion: The findings in this study suggest that inexperienced nurses believe they have a lack of practical skills. All of them say that there is a lack of training and good opportunities to practice and maintain their practical skills. Therefore, hospitals should strive to increase RNs' competence in performing venous cannulation in order to reduce the complications and discomfort resulting from unsuccessful attempts to insert PVCs. Nurse anaesthetists have the necessary skills and the RNs on the wards wish to use them as resource persons when practising PVC insertion. 
Peripheral venous cannulation is the most routinely performed invasive procedure carried out by registered nurses (RNs) in hospitals (1). It is a complicated procedure and for successful completion, it requires knowledge of anatomy (suitable veins and avoidance of nerve and arterial injury), hygiene (aseptic techniques) and technical skills (choice of size of PVC and insertion techniques) (2).

An estimated 60-80 per cent of all hospital patients need intravenous treatment with at least one PVC (3). The definition of a difficult PVC placement is two or more unsuccessful skin punctures. One-third of adult patients $(4,5)$ are assumed to have difficult venous access, which further complicates the performance of the procedure.

An unsuccessful placement of the PVC may delay the commencement of vital treatment. When there are repeated attempts to insert the PVC, the patient is exposed to painful needlesticks and discomfort. Moreover, complications such as bleeding, infection, and arterial and nerve injury may occur around the insertion site after unsuccessful cannulation (5-7).

It has previously been demonstrated that nursing students receive limited training in the PVC procedure and opportunities to practise this are fairly random. The Bachelor's degree nursing programme offers students a digital presentation of the procedure and gives students practice using a plastic training arm. The individual student is then dependent on the work placement institution where insertion of the PVC can be practised under the guidance of a placement supervisor $(7,8)$. 
Several studies present a variety of training programmes in which nursing students simulate PVC insertion $(9,10)$. Inadequate practical training while on placement makes it difficult to improve. A number of studies describe specialist nurses' experiences of difficult PVC insertions, mastering PVC insertion and complications with venous cannulation (11-13). Few studies highlight the experiences of RNs in wards with the PVC procedure.

\section{The objective of the study}

The objective of the study was to describe registered nurses'(RNs) experiences when inserting PVCs and the challenges they face. Such knowledge can help identify measures that will improve RNs' skills, thus boosting patient safety and improving their experience of the PVC procedure. The study focused on the following research question:

'What assessments and measures do RNs carry out when they are to insert a PVC, and what challenges do they face when performing the procedure?'

\section{Method}

\section{Design}

The study had a qualitative descriptive design since we wished to describe RNs' experiences and the challenges they faced $(14,15)$. The first author conducted two focus group interviews with four and five participants respectively in order to collect data. The number of participants is regarded as favourable in terms of group dynamics and maintaining an overview of the group (16).

The limited number of participants and choice of research method mean that the results cannot be generalised, but the findings are interesting and may promote quality improvement and further research. 


\section{Participants and recruitment}

The first author invited 150-200 RNs in six different wards at a Norwegian hospital to take part in the study. Each ward had approximately 20 patients requiring a PVC. The participants were familiar with the PVC procedure and were therefore suitable informants (14).

Written information was sent to heads of department, who passed on the information. Fourteen RNs contacted the first author directly by email to express their interest. A total of nine informants turned up for the focus group interview. The recruitment process lasted for three months - from November 2018 until January 2019.

\section{Data collection}

We devised themes for the semi-structured interview guide based on the research question (see Table 1). These themes were the starting point for the focus group interviews and helped to clarify the context, assessments and measures related to the PVC procedure as well as the challenges faced by RNs. Meanwhile, we wanted the informants to speak freely and to feel that they had the support of others in the group when expressing their opinions (16).

For each of the interviews, we engaged a co-moderator to assist the moderator (the first author) in encouraging the informants to keep to the themes given in the semi-structured interview guide (15). The interviews lasted just under 40 minutes and were audio recorded. During the focus group interviews, we asked the informants further probing and confirmatory questions (17) to ensure that we understood their answers. 
Table 1. Interview guide

\begin{tabular}{|c|c|c|}
\hline Theme & Thematic questions & Keywords for possible follow-up questions \\
\hline $\begin{array}{l}\text { Experience/challenges in } \\
\text { inserting PVCs }\end{array}$ & $\begin{array}{l}\text { Do you have any thoughts about how often } \\
\text { you insert a PVC? } \\
\text { How often are you successful? What makes } \\
\text { you successful? } \\
\text { Do you have long experience in inserting } \\
\text { PVCs? } \\
\text { Do you feel confident when you have to } \\
\text { insert a PVC? } \\
\text { What makes it difficult to insert a PVC? } \\
\text { How many times do think it is reasonable to } \\
\text { try to insert the PVC before calling for help? }\end{array}$ & $\begin{array}{l}\text { Once a week, more often or less often? } \\
\text { How do you think experience can influence } \\
\text { the successful insertion of a PVC? } \\
\text { What makes you feel confident? } \\
\text { What makes it difficult to insert a PVC? }\end{array}$ \\
\hline The patient's remarks & $\begin{array}{l}\text { Do patients say anything when they are to } \\
\text { get a PVC? }\end{array}$ & $\begin{array}{l}\text { Does the patient say anything about pain, the } \\
\text { site selected, who is to insert the needle? }\end{array}$ \\
\hline $\begin{array}{l}\text { Nursing skills, initiatives prior } \\
\text { to needle insertion }\end{array}$ & $\begin{array}{l}\text { What steps do you take before inserting a } \\
\text { PVC? } \\
\text { Is it normal practice in the department to } \\
\text { consult another registered nurse (RN) in the } \\
\text { department if it proves difficult to insert the } \\
\text { PVC? } \\
\text { What would make you more confident in } \\
\text { relation to inserting a PVC when it appears } \\
\text { to be difficult? }\end{array}$ & $\begin{array}{l}\text { What steps do you take before you insert the } \\
\text { needle? } \\
\text { Do you do anything differently when it looks } \\
\text { difficult? } \\
\text { Who do you consult? } \\
\text { Are you familiar with the procedure for PVC } \\
\text { assistance? } \\
\text { Is it sometimes the case that PVC assistance } \\
\text { cannot come or that they are unsuccessful? }\end{array}$ \\
\hline
\end{tabular}

Measures for improving

performance

\section{Data analysis}

We analysed the data using thematic analysis in line with a six-step model inspired by Braun and Clarke (18) (Table 2). We organised and interpreted the data using this model, which allowed us to identify thematic codes using the research question without a theoretical framework. Thematic codes with the same meaning were then combined into one theme. The informants' perspectives emerged through our listening carefully to the data, transcribing it and then reviewing the transcriptions several times (15).

The two focus group interviews were interpreted across the groups on the basis of similarities between the informants in both groups, such as a variety of work experience and the inclusion of representatives from different wards. All dialects were transcribed in standard Norwegian to prevent identification of the informants (16). 


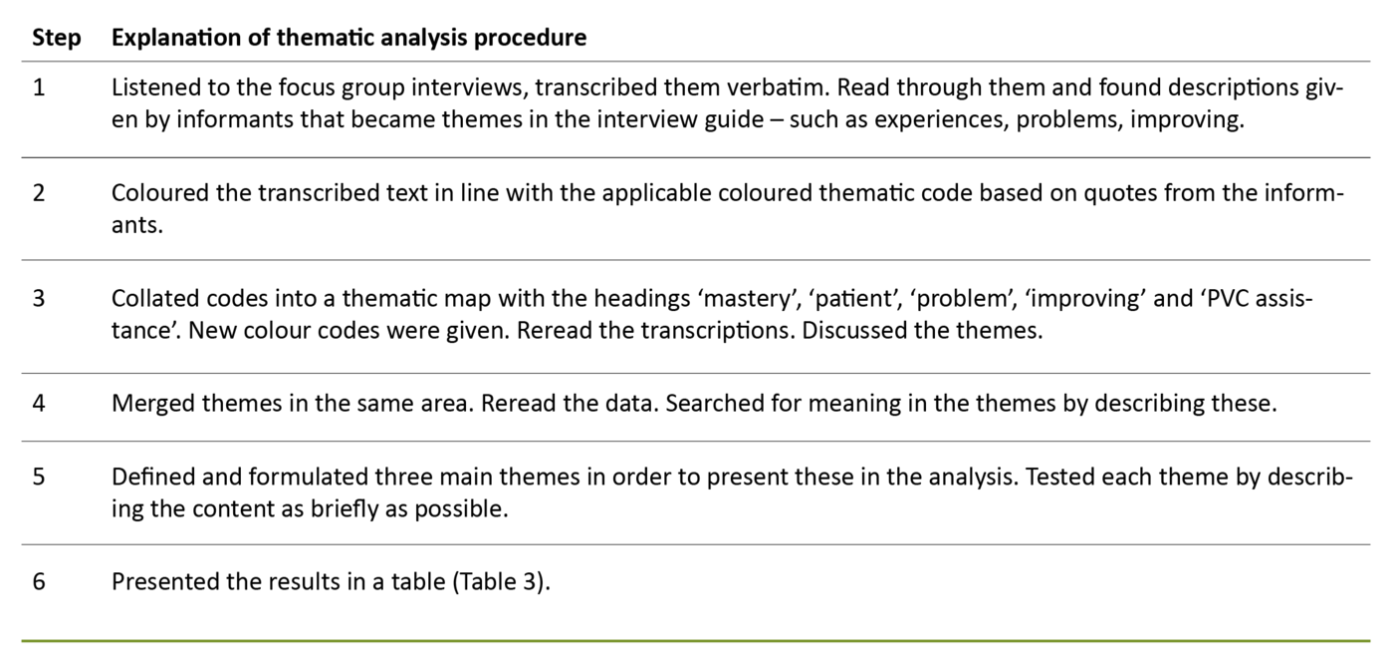

\section{Research ethical considerations}

The study was approved by the Norwegian Centre for Research Data (reference number 929402) and the specialist department at the hospital in question. The data were stored in accordance with current practice at the University of Oslo. We obtain written informed consent from all participants. Prior to the start of the interviews, both the co-moderator and the participants were requested to abide by the duty of confidentiality (14).

\section{Results}

Four of the informants had from one to four years' experience of PVCs, and five had more than five years' experience (described below as 'experienced'). Eight of the informants were women, and one was a man.

On average, the informants' attempted to insert a PVC two to three times a week. All the informants were aware that local PVC assistance was given by ICU nurses. Moreover, nurse anaesthetists with their specialist competence in venous cannulation were regarded as resource persons when PVC assistance proved unsuccessful or was not available.

The data analysis resulted in three main themes: 1) patient-related factors and interaction with the patient, 2) factors related to the RNs and working conditions, and 3) skills development (Table 3). 
Table 3. Result of analysis with description of themes and sub-categories

\begin{tabular}{|c|c|c|}
\hline Theme & Description of theme & Sub-categories \\
\hline \multirow[t]{2}{*}{$\begin{array}{l}\text { Patient-related factors and } \\
\text { interaction with the patient }\end{array}$} & \multirow[t]{2}{*}{$\begin{array}{l}\text { Describes patient-centred factors } \\
\text { that make PVC insertion challeng- } \\
\text { ing. Describes the RNs' communi- } \\
\text { cation with the patient during PVC } \\
\text { insertion. }\end{array}$} & $\begin{array}{l}\text { Anatomical difficulties: } \\
\text { Non-visible, non-palpable veins. } \\
\text { Rolling, thin, collapsed veins. } \\
\text { Dark skin colour. } \\
\text { Substance abusers. }\end{array}$ \\
\hline & & $\begin{array}{l}\text { Pain: younger patients, often men } \\
\text { Some have wishes regarding the insertion site: } \\
\text { Arm they use least, not near a joint, does not } \\
\text { impede activity. } \\
\text { Some patients want a nurse 'dressed in green' to } \\
\text { perform the needle insertion (nurse anaesthetist): } \\
\text { Earlier experience with difficult venous access. }\end{array}$ \\
\hline \multirow[t]{4}{*}{$\begin{array}{l}\text { Factors related to the RNs } \\
\text { and working conditions }\end{array}$} & \multirow[t]{4}{*}{$\begin{array}{l}\text { RNs' description of their own skills } \\
\text { and decisions when a PVC is to be } \\
\text { inserted, and factors that make the } \\
\text { PVC procedure difficult. }\end{array}$} & $\begin{array}{l}\text { Experience: } \\
\text { Experienced RNs perform needle insertions more } \\
\text { frequently and are more often successful than less } \\
\text { experienced RNs. } \\
\text { Needle insertion requires courage. } \\
\text { Little training both during nursing education and } \\
\text { clinical updates. }\end{array}$ \\
\hline & & $\begin{array}{l}\text { Mastery: } \\
\text { Colleague shows trust. } \\
\text { Practice/maintain their skills in performing the } \\
\text { procedure. }\end{array}$ \\
\hline & & $\begin{array}{l}\text { Decisions: } \\
\text { Carry out needle insertion themselves/ask a colleague } \\
\text { before calling on PVC assistance or a nurse } \\
\text { anaesthetist. } \\
\text { Insert needle more than twice when help does not } \\
\text { arrive. } \\
\text { Heat the vein, assume a suitable position and ensure } \\
\text { adequate lighting. } \\
\text { Hand over work tasks to colleagues during the PVC } \\
\text { procedure. }\end{array}$ \\
\hline & & $\begin{array}{l}\text { Poor working conditions, cramped three-bed room } \\
\text { Time conflicts: } \\
\text { Many work tasks in own department. Time-consum- } \\
\text { ing PVC procedure. } \\
\text { Ongoing programme, and a lack of resources in the } \\
\text { surgical department and the ICU, where help can be } \\
\text { found. } \\
\text { Time spent getting help and transporting patients to } \\
\text { where help is available. }\end{array}$ \\
\hline Skills development & $\begin{array}{l}\text { RNs' descriptions of methods that } \\
\text { can improve their PVC insertion } \\
\text { skills. }\end{array}$ & $\begin{array}{l}\text { Teaching: } \\
\text { A nurse anaesthetist teaches RNs and practical train- } \\
\text { ing is given. } \\
\text { Observing the specialist nurse performing needle } \\
\text { insertion. } \\
\text { Supervised practice in the surgical department. }\end{array}$ \\
\hline
\end{tabular}

\section{Patient-related factors and interaction with the patient}

The informants mentioned several anatomical factors that could make insertion of a PVC difficult. Patients with thin, non-visible or non-palpable veins were regarded as particularly challenging. It was difficult when the patient was agitated or pulled their hand back when the needle was inserted. Patients who had been subject to many needlesticks with the result that there few available sites for inserting a PVC were seen as almost impossible to cannulate: 
'The worst are those who have multiple needle punctures. When you can't see or feel the vein, you have no chance of finding out where it is' (informant 5).

The informants regarded the pain felt by the patient during the procedure as a complicating factor that they tried to take into account. They agreed that young patients found it most painful, and they saw that some patients dreaded the procedure. Several informants believed that patients intuitively realised that the needlestick was necessary and accepted this without protest:

'Patients understand when I come along with the cannula box' (informant 3).

The RNs said that some patients asked for the nurse anaesthetist to insert the needle because it had been difficult to place the PVC earlier. They did not want to experience too many painful needlesticks. Several RNs reported that patients often said the following:

'It's usually the people dressed in green who come and insert needles' (informant 4).

The RNs reported that they often tried to respect this wish, but some informants managed to persuade the patient to let them try, and experienced RNs said that they were sometimes successful.

The informants remarked that some patients expressed a wish as to where RNs should place the PVC. They mentioned the arm they used least, a site that was not close to a joint and that did not impede activity. The RNs said it could be challenging to meet these wishes.

\section{Factors related to the $\mathbf{R N s}$ and working conditions}

The RNs agreed that good working conditions were a prerequisite for successful insertion of the PVC but found this could be challenging: 
'It's cramped and difficult with cases and shoes and tables everywhere' (informant 4).

The informants were keen to place the PVC themselves and helped each other before summoning help from others. On occasion, the RNs inserted the needle more than twice, and they said it was difficult to spend enough time on the procedure:

'We just keep on inserting the needle, we do, and yes, you can get help 'eventually', but that can take a few hours' (informant 9).

This applied when there were time conflicts. The RNs described time conflicts as arising when they had many work tasks that needed to be carried out at the same time in different places, and it was difficult to prioritise. The RNs found that time conflicts, in both their own department and among the PVC assistance providers, could lead to a delay in treatment and many needle insertions. They were very focused on 'getting the PVC job done', and it could be difficult to find enough time to carry out the PVC procedure. Consequently they called for PVC assistance or a nurse anaesthetist to get the job done.

RNs experienced a feeling of mastery when their colleagues showed their trust by asking them for help to insert a PVC, and when they managed this several times in succession. Experienced RNs encouraged less experienced RNs to try to insert the needle themselves, and they attained greater confidence through successfully placing the PVC more often than other less experienced RNs:

'I've found something I like, something I'm good at. I've done it quite a few times now' (informant 6).

\section{Skills development}

All the informants regarded practical supervision as a means of developing their skills in performing the PVC procedure: 
'I like to watch how the PVC assistance providers manage this. I ask for tips and so on, but in our very busy workday we don't have time for that, of course' (informant 2).

\section{«The RNs wished for short training sessions with a nurse anaesthetist, for example, a few times a month, or to have supervised practice in the surgical department.»}

The RNs wished for short training sessions with a nurse anaesthetist, for example, a few times a month, or to have supervised practice in the surgical department. The informants said that earlier they had had some training days in the course of the year but because of the increased workload and higher operating costs, it was no longer easy to obtain the resources for routine competence enhancement:

'Earlier we had training sessions every Wednesday, then it changed to every second Wednesday and then to every fourth Wednesday, and now we don't really know' (informant 9).

Most RNs were familiar with this situation. A lack of training during their nursing education and poor follow-up of the PVC procedure in clinical practice meant that several RNs were afraid to attempt needle insertion:

'It was scary trying to insert a needle when I was a newly graduated nurse because at nursing college, we only practised on those rubber hands' (informant 8 ).

Several of the RNs with little experience said that they dreaded inserting a needle, and even experienced RNs who had not performed the PVC procedure regularly were reluctant:

'I feel the need for a bit more training. It's a while since we attended nursing college' (informant 5). 
The RNs' remarks indicate that they themselves wanted to improve their PVC insertion skills. They wanted more practical training with a nurse anaesthetist and more satisfactory clinical training as part of nursing education. They also wanted training days in their department to be restored.

\section{Discussion}

The results of this study show that RNs face complex challenges when inserting PVCs. These challenges can be summarised as challenges vis-à-vis the patient, the organisation of the hospital or the RNs themselves.

\section{Challenges vis-à-vis the patient}

The experiences of patients and RNs' skills in performing the PVC procedure have not been adequately investigated (11). The informants described how non-visible veins and untidy and cramped wards made it difficult to place the PVC. Such factors have proved to increase the length of time spent on the procedure in addition to creating anxiety and chaotic conditions in patient-centred situations $(19,20)$.

Patients have very divergent perceptions of pain when a needle is inserted - everything from mild discomfort to extreme pain, and some patients regard the PVC as 'a necessary evil' (21). The informants in this study stated that patients accepted the PVC without particular questions or protests even though the RNs found that some patients said it could be painful. The explanation may be that patients accept more painful procedures when they understand the need for the treatment.

\section{«Good communication between patient and $R N$ is essential for the patient's comfort.»}


Several informants had experienced that patients themselves requested that the nurse anaesthetist should be called on to place the PVC because the RNs on the ward had not been successful earlier. The informants very often took this wish into account. Patients who have earlier discovered that they have difficult venous access are more anxious about needle insertions, and each unsuccessful attempt may cause them more pain (21).

Good communication between patient and $\mathrm{RN}$ is essential for the patient's comfort. Moreover, it is important that the person performing the procedure possesses good skills and that the insertion site is acceptable $(7,11)$. The informants said that patients wanted the PVC to be inserted at a site that did not hinder mobility.

Most informants asserted that it was important to dare make an attempt to place the PVC. Therefore experienced nurses tried to place the PVC even though the patient indicated that others had had problems and that it could be difficult. Such decisions suggest that the informants trusted in their own skills, which can be vital for success with the procedure (12).

Clinical assessment and confident decision-making when performing procedures improve with experience. The ability to trust one's own skills, work swiftly and perform qualitative analysis in one's work is described as expert level (22).

\section{Challenges vis-à-vis the organisation of the hospital}

The informants referred to hectic shifts with time conflicts, such as responsibility for many patients and many work tasks, as the underlying reason for it being challenging to get enough time to place the PVC. Such time challenges are reflected in studies reporting that RNs find that they spend a lot of time on tasks that others could have carried out. They are thus prevented from prioritising key work tasks and patient-centred nursing $(23,24)$. 
Research shows that competence, self-confidence and teamwork are criteria for good decision-making (25). All the informants described how they almost always asked for help from a colleague before calling for PVC assistance. Good collegial relationships in the wards are seen as an important resource. RNs in supportive environments are capable of deciding on sound initiatives in their nursing tasks (24).

The RNs explained that weekly training meetings had been reduced to more sporadic competence enhancement sessions because of a lack of resources. They viewed this as a step backwards in terms of maintaining their PVC skills. Economic factors carry more weight than the prioritising of patient-centred tasks (23). Training and follow-up are needed to improve skills in inserting PVCs $(26,27)$.

During their studies, nursing students can increase their skills in relation to venous cannulation by registering their self-guided practice sessions and using checklists aided by practical training videos, rubber training hands and simulations (2, 9, 10, 27).

Skills enhancement would mean that RNs could swiftly identify patients who have difficult venous access and need the help of a nurse anaesthetist when it comes to needle insertion. If necessary, the nurse anaesthetist can use alternative methods such as ultrasound $(5,7)$. Unnecessary needlesticks can then be significantly reduced.

\section{Challenges vis-à-vis the RN}


The balance between attempting to place the PVC themselves and identifying patients who need help from someone with specialist PVC skills can be difficult for RNs $(4,12)$. When the ward was busy, the informants asked a random colleague or requested PVC assistance, depending on who was available. Patients could experience two needlesticks from three to four people before the PVC was placed - six-eight needlesticks altogether (one or two RNs on the ward, the PVC assistance provider and finally a nurse anaesthetist).

Consequently, it is crucial that RNs are aware of their own limitations and inform others of their limited experience and skills when the procedure is to be performed so as to avoid painful needlesticks and ensuing complications (26).

One reason that RNs seldom inserted needles more than twice before calling for help or sometimes called for help before trying to carry out needle insertion themselves may be that they wanted to protect the patients from pain. The informants found that giving the patient information and maintaining a calm atmosphere were positive factors even though they were often too busy to take this into consideration.

The informants used recognised theory-based strategies when preparing the PVC procedure, such as warming the vein, ensuring good lighting, and sitting down and informing the patients. RNs with long experience, defined as being on the level between proficient and expert in Benner's stages of clinical competence (28), had more self-confidence and felt they were more often successful than less experienced RNs.

\section{«The experienced informants tried to encourage their less experienced colleagues to insert the PVC themselves first.»}


Those with less experience can be defined as being on the level between advanced beginner and competent nurse in this model. Recognition from colleagues gave all the informants a feeling of self-confidence, support and increased mastery when they were to place the PVC.

The experienced informants tried to encourage their less experienced colleagues to insert the PVC themselves first. Expert nurses with a broad background, situational understanding and good technical skills taught the advanced beginners who needed support in terms of their clinical understanding (27). RNs with self-perceived good skills have reported successfully placing PVCs more often than RNs without these skills (24).

Placing a PVC normally generates some procedurerelated pain $(21,26)$. Some of the informants were concerned to protect patients from such pain, but nevertheless felt that most patients accepted PVCs without undue protest. RNs have a duty to do no harm but rather facilitate good treatment, and to do their best to minimise pain related to procedures $(29,30)$. When RNs feel that the patient has a medical need for a PVC, this justifies the pain inflicted.

\section{Strengths and limitations of the study}

The first author is a nurse anaesthetist and has therefore considerable experience and knowledge of the topic, which represents a strength of the study (14). Meanwhile, this can have led to unforeseen bias with a lack of follow-up questions in the focus group interviews so that not all the participants' remarks were adequately explored $(15,16)$. 
When interested participants come forward themselves, there is reason to assume that they have reflected more on PVC insertion than most RNs. A greater number of focus group interviews could have strengthened the study, and individual interviews might be a suitable data collection method for further exploration in depth $(14,15)$. Since only nine participants enrolled on the study, there was little opportunity to influence the composition of the groups.

\section{Conclusion}

Even though inserting a PVC is a normal clinical nursing task, the limited sample of RNs in this study find that the procedure is complex and sometimes difficult to perform. Patients are often subject to multiple needlesticks when the PVC is to be placed. This can lead to complications for the patient and delay medical treatment.

The results of the study show that RNs supported each other and used recognised strategies to place the PVC but they identified a number of challenges. The informants regarded it as almost impossible to insert needles in patients with non-visible and non-palpable veins, and RNs experienced constant time conflicts that could diminish their ability to concentrate on the PVC procedure.

The informants wanted instruction and training in PVC insertion both in nursing education and in clinical practice since this can increase RNs' PVC skills, thereby reducing the number of painful needlesticks with following complications. Greater knowledge can also result in RNs prioritising the insertion of PVCs in line with other nursing tasks.

Patients with difficult venous access can be identified at an early stage so that the nurse anaesthetist can use the resources in their own department when a patient needs PVC assistance. In this way, an anaesthetist nurse can place the PVC at an early stage in the case of patients with difficult venous access. 


\section{The study's contribution of new knowledge}

- The registration of data shows that nurse anaesthetists must help with PVC insertion in wards several times a day. RNs and nurse anaesthetists have different areas of competence and knowledge, and patients have the right to get help from those who are most skilled at the task. Earlier research shows that PVC insertion is a complicated nursing procedure that may harm the patient if unsuccessful. There has been considerable research focus on the procedure itself, complications that arise and different training programmes. There is little research on RNs' experiences with the procedure, particularly as regards difficult venous access.

- RNs who carry out the procedure themselves can best describe their own experiences, what can be difficult and what measures they adopt. For this reason, we used focus group interviews to obtain such data.

- The study helps to draw attention to the RN's own remarks about a common but frequently difficult procedure. Specific measures emerged in the study that can enhance nursing competence, and it turn this will contribute to increased patient safety.

\section{References}

1. Webster J, Osborne S, Richard C, Marsh N.

Clinically-indicated replacement versus routine replacement of peripheral venous catheters. Cochrane Database of Systematic Reviews. 23.01.2019.

DOI:10.1002/14651858

2. Ahlin C, Klang-Søderkvist B, Johansson E, Bjørkholm M, Løfmark A. Assessing nursing student's knowledge and skills in performing venipuncture and inserting peripheral venous catheters. Nurse Education in Practice. 2017;23:8-14.

3. Dychter SS, Gold DA, Carson D, Haller M. Intravenous therapy: a review of complications and economic considerations of peripheral access. Journal of Infusion Nursing. 2012;35(2):84-91.

4. Sou V, McManus C, Mifflin N, Frost SA, Ale J, Alexandrou E. A clinical pathway for the management of difficult venous access. BioMed Central Nursing. 2017;16(64):64. 
5. Partovi-Deilami K, Nielsen J, Moller A, Nesheim S, Jorgensen V. Effect of ultrasound-guided placement of difficult-to-place peripheral venous catheters: a prospective study of a training program for nurse anesthetists. American Association of Nurse Anesthetists Journal. 2016;84(2):86-92.

6. Fields J, Piela N, Au A, Ku B. Risk factors associated with difficult venous access in adult ED patients. Am J Emerg Med. 2014;32(10):1179-82.

7. Carr P, Higgins NS, Cooke ML, Mihala G, Rickard CM. Vascular access specialist teams for divice insertion and prevention of failure. Cochrane Database of Systematic Reviews. 20.03.2018. DOI:

10.1002/14651858.CDO11429

8. Norges teknisk-naturvitenskapelige fakultet (NTNU). Pensum: Innleggelse av perifert venekateter (PVK) på IV pad (Atrappen). NTNU. Available at: https://www.ntnu.no/documents/1266567701/12691696 81/PVK+og+IV+Pad/aoaa77bd-e49a-49bb-9ao834832f2f68f5 (downloaded 20.01.2021).

9. Ravik M, Havnes A, Bjørk IT. Conditions affecting the performance of peripheral vein cannulation during hospital placement: a case study. Nursing Research and Practice. 2017;2017:9748492. DOI: $\underline{10.1155 / 2017 / 9748492}$

10. Simonetti V, Comparcini D, Miniscalco D, Tirabassi R, Giovanni DP, Cicolini G. Assessing nursing students' knowledge of evidence-based guidelines on the management of peripheral venous catheters: a mulitcentre cross-sectional study. Nurse Education Today. 2019;73:77-82.

11. Larsen E, Keogh S, Marsh N, Rickard C. Experiences of peripheral IV insertion in hospital: a qualitative study. British Journal of Nursing. 2017;26(19):S18-S25. 
12. Forsberg A, Engstrøm A. Critical care nurses' experience of performing successful peripheral intravenous catheterization in difficult situations. Journal of Vascular Nursing. 2018;36:64-70.

13. Woody G, Davis BA. Increasing nurse competence in peripheral intravenous therapy. Journal of Infusion Nursing. 2013;36(6):413-9.

14. Polit D, Beck C. Nursing Research. Generating and assessing evidence for nursing practice. 1oth ed. Philadelphia: Wolters Kluwer Health; 2017.

15. Kvale S, Brinkmann S. Det kvalitative forskningsintervju. Oslo: Gyldendal Akademisk; 2017.

16. Malterud K. Fokusgrupper som forskningsmetode for medisin og helsefag. Oslo: Universitetsforlaget; 2012.

17. Green J, Thorogood N. Qualitative methods for health research. 3rd ed. London: Sage Publications; 2018.

18. Braun V, Clarke V. Using thematic analysis in psychology. Qualitative Research in Psychology. 2006;3(2):77-101.

19. Rodriguez-Calero M, Fernandez-Fernandez I, Molero-Ballester L, Matamalas-Massanet C, MorenoMejias L, de Pedro-Gomez J, et al. Risk factors for difficult peripheral venous cannulation in hospitalised patients. Protocol for a multicentre case-control study in 48 units of eight public hospitals in Spain. British Medical Journal Open. 2018;8(2)e-020420.

20. Shaw S. Locating difficult veins for venepuncture and cannulation. Nursing Standard. 2017;31(25):62-71.

21. Robinson-Reilly M, Paliadelis P, Cruickshank M. Venous access: the patient experience. Support Care Cancer. 2016;24(3):1181-7. 
22. Higgs J, Jones MA, Loftus S, Christensen N, eds. Clinical reasoning in the health professions. 3 rd ed. Butterworth Heinemann, Elsevier; 2008.

23. Bergsagel I. 6 av 10 sykepleiere bruker daglig tid på oppgaver de mener andre burde utføre. Sykepleien. 06.02.2019.

24. Wilson B, Harwood L, Oudshoorn A, Thompson B. The culture of vascular access cannulation among nurses in a chronic hemodialysis unit. Canadian Association of Nephrology Nurses and Technologists Journal. 2010;20(3):35-42.

25. Hagbaghery M, Salsali M, Ahmadi F. The factors facilitating and inhibiting effective clinical decisionmaking in nursing: a qualitative study. Bio Med Central Nursing. 2004;3(1):2.

26. Jacobson A. Cognitive-behavioral interventions for IV insertion pain. AORN Journal. 2006;84(6):103148.

27. Collins M, Phillips S, Dougherty L, de Verteuil A, Morris W. A structured learning programme for venepuncture and cannulation. Nursing Standard. 2006;20(26):34-40.

28. Benner P. From novice to expert. The American Journal of Nursing. 1982;82(3):402-7.

29. Ichimura M, Sasaki S, Mori T. Tapping but not massage enhances vasodilatation and improves venous palpation of cutaneous veins. Acta Medica Okyama. 2015;69(2):79-85.

30. Norsk Sykepleierforbund, Rådet for sykepleieetikk. Yrkesetiske retningslinjer for sykepleiere. Oslo: Norsk Sykepleierforbund; 2001. Available at: https:/www.nsf.no/visartikkel/2193841/17036/Yrkesetiske-retningslinjer-forsykepleiere (downloaded 22.05.2019). 
